\title{
Letter to the editor concerning the Editorial "Innovation in orthopaedic surgery as it relates to evidence-based practice" by M. Hofbauer, B. Muller, C. D. Murawski, J. Karlsson and Freddie H. Fu
}

\author{
Markus P. Arnold · Michael T. Hirschmann
}

Received: 19 May 2013/Accepted: 24 August 2013/Published online: 8 September 2013

(C) Springer-Verlag Berlin Heidelberg 2013

\section{Dear colleagues,}

With keen interest, we read your recent editorial contemplating the important question, What the main driving force for innovation in orthopaedics is? We feel that some key questions should be discussed in detail:

Is it really for the sake of the patient when the industry, aiming for an increase of market shares and sales puts out new developments of products every 2-3 years? What is the role of consultant payments to key opinion leaders with regards to widespread introduction of innovative products? How can we make sure that new developments are better or at least equal to well proven ones? How to measure the benefit for the patient? Should we increase the administrative and reporting hurdles for innovations?

As researchers and orthopaedic surgeons, we sometimes tend to see the glass half-full rather than half-empty when it comes to innovations. As member of the developing group of an innovative product, we have committed ourselves to a new idea, believe in the benefit for our patients and hence are keen to promote it. By promoting a novel development, one may nationally and internationally get more recognized. One needs to be very self-critical here not to forget the initial driving force. It should be improvement of patient's care, not personal benefits, which may come along with it.

Do we need an ethical codex for working together with industry partners on the development and promotion of innovations? Two worlds, the medical and the industry

M. P. Arnold $(\varangle) \cdot$ M. T. Hirschmann

Department of Orthopaedic Surgery and Traumatology,

Kantonsspital Baselland/Bruderholz, 4101 Bruderholz,

Switzerland

e-mail: markus-p.arnold@unibas.ch world, are in some ways diametrically opposed. On the other hand, these two worlds need each other. It is a very thin line we walk between these two worlds when we work together with industry partners to develop new techniques or implants. Usually, the industry does not come up with ideas making their life more difficult. It is we, the orthopaedic surgeons, who should define rules of cooperation with industry partners. Should these also include a pathway for introduction of novel products to our patients? What kind of research has to be performed to use it in our patients: computer simulation, mechanical testing, animal studies, cadaver studies, pilot studies?

In your editorial, several examples were given in which the industry had pushed a product strongly into the market which turned out to be not beneficial or even harmful to the patient, like failing artificial ligaments, metal on metal hip implants and others.

In some medical innovations, the product, the idea or surgical concept itself is not the problem, but when introduced to less-experienced surgeons, the problem starts. Unfortunately, the industry keeps on recommending and promoting it to every orthopaedic surgeon, as their main goal is to increase the volume of sales. As a typical example, which was not mentioned in the editorial, doublebundle ACL reconstruction can be considered. We learnt from recent well-performed biomechanical as well as clinical studies that a well-performed double-bundle ACL might result in slightly superior outcomes, for the price of an important increase in surgical complexity. In expert hands, there is no problem. Others might struggle. A solution might be to introduce new techniques on a "no train-no use" policy, giving innovators the chance to pass on in-depth knowledge from designer to user.

Even then there is no guarantee that we will not do harm to our patients when we set foot on new and uncharted territory. 